Review Article

\title{
Methane Medicine: A Rising Star Gas with Powerful Anti-Inflammation, Antioxidant, and Antiapoptosis Properties
}

\author{
Yifan Jia, ${ }^{1}$ Zeyu Li, ${ }^{1}$ Chang Liu $\mathbb{D}^{1,2}$ and Jingyao Zhang $\mathbb{D}^{1,2}$ \\ ${ }^{1}$ Department of Hepatobiliary Surgery, The First Affiliated Hospital of Xi'an Jiaotong University, Xi'an, Shaanxi 710061, China \\ ${ }^{2}$ Department of SICU, The First Affiliated Hospital of Xi'an Jiaotong University, Xi'an, Shaanxi 710061, China
}

Correspondence should be addressed to Chang Liu; liuchangdoctor@163.com and Jingyao Zhang; you12ouy@163.com

Received 19 November 2017; Revised 12 January 2018; Accepted 21 January 2018; Published 18 March 2018

Academic Editor: Ryuichi Morishita

Copyright (C) 2018 Yifan Jia et al. This is an open access article distributed under the Creative Commons Attribution License, which permits unrestricted use, distribution, and reproduction in any medium, provided the original work is properly cited.

\begin{abstract}
Methane, the simplest organic compound, was deemed to have little physiological action for decades. However, recently, many basic studies have discovered that methane has several important biological effects that can protect cells and organs from inflammation, oxidant, and apoptosis. Heretofore, there are two delivery methods that have been applied to researches and have been proved to be feasible, including the inhalation of methane gas and injection with the methane-rich saline. This review studies on the clinical development of methane and discusses about the mechanism behind these protective effects. As a new field in gas medicine, this study also comes up with some problems and prospects on methane and further studies.
\end{abstract}

\section{Introduction}

Methane, the simplest alkane, is the most plentiful organics on earth and has been studied for hundreds of years since its discovery in 1778 . Being the main component of natural gas, methane is used as gas fuel. In past decades, it has been proven to be related to global warming since it contributes $20 \%$ of the greenhouse gases in the atmosphere and the concentration has raised rapidly [1]. In the clinic area, it was deemed antecedently that human bodies could not use methane. The endogenous methane is mainly excreted as flatus and it can also enter into the blood circulation and be exhaled by the respiratory system [2]. However, scientists recently reveal the biological effect of methane, especially the properties of anti-inflammatory, antioxidant, antiapoptosis and other clinic effects of methane, remains to be discovered.

There is about $200 \mathrm{ml}$ gas in human enteric canal which is produced from various processes including air-swallowing, diffusion from blood, and biochemical reactions caused by bacteria in the enteric canal [3]. The proportion of healthy adult who can be detected with methane is more than 30\%-50\% worldwide [2, 4]. Anaerobic flora converts undigested carbohydrates into different organic compound including methane gas during fermentation [5]. To be more precise, methane is produced by a unique metabolic process, in which carbon dioxide is converted into methane with the hydrogen from anaerobic bacterial fermentation. Methanobrevibacter smithii and Methanospaera stadmagnae are the main methanogen in the intestinal tract, but in the oral cavity, Methannobrevibacter oralis is the chief methanogen and can lead to dental disease $[6,7]$.

\section{Delivery of Methane}

2.1. Inhalation. It is generally acknowledged that methane is a simple nontoxic asphyxiant, which means it is inherently nontoxic. Methane can be delivered via inhalation through many methods, including ventilator and facemask. As a flammable and explosive gas, the safe concentration of methane in pure oxygen is $4.9 \%$. Nevertheless, methane should be used and stored with reliable tools and safety must always be the first concern. According to the study of Boros et al., the gas mixture of oxygen and methane $\left(21 \% \mathrm{O}_{2}+2.5 \%\right.$ $\mathrm{CH}_{4}$ ) is safe for rodents [8].

2.2. Injection of Methane-Rich Saline. Although inhalation is efficient and convenient, methane will bring the safety 
concern of explosion. Injection may make the delivery more safe and precise. A flexible way to produce a supersaturated methane-rich saline is set up through dissolving methane into sterilizing saline for 6 hours under the pressure of $0.4 \mathrm{MPa}$ [9]. As methane gas is similar to hydrogen gas in chemical aspect, some researchers [10] used the same method to measure the concentration of methane as Ohsawa et al. described in hydrogen [11].

\section{The Biological Effects of Methane}

\subsection{Liver}

3.1.1. Acute Liver Failure (ALF). Acute liver failure (ALF) is the clinical manifestation of sudden and severe hepatic injury [12]. In the United States, over $6 \%$ of liver-related mortality was caused by ALF in 2005 [13]. Necrosis and apoptosis of hepatocytes induced by infection, chemical, or biological toxins are the dominant pathological causes of acute liver failure [13-15]. In a carbon tetrachloride- $\left(\mathrm{CCl}_{4^{-}}\right)$induced acute liver injury mice model, methane showed a potential to be a therapeutic agent for ALF. Yao et al. showed that methane-rich saline could upregulate the expression of IL10 by activating the PI3K/AKT/GSK-3 $\beta$ pathway, which would suppress the NF- $\kappa \mathrm{B}$ and MAPK pathways and raise anti-inflammatory properties [16].

3.1.2. Autoimmune Hepatitis (AIH). Autoimmune hepatitis $(\mathrm{AIH})$ is a generally progressive chronic inflammation disease of the liver that occurs when the self-tolerance is broken down and hepatic cells are attacked by immune system accidentally [17]. The etiological and pathological mechanism of autoimmune hepatitis still remains unclear despite the genetic factor and environmental triggers, including infection, familial inheritance, and gender, are involved in the progress of the AIH [18]. Methane-rich saline showed kind of protection to concanavalin A-induced autoimmune hepatitis in the study of He et al. [19]. According to the study, the elevated serum aminotransferase levels in concanavalin Ainduced autoimmune hepatitis mice model were reduced obviously after methane treatment. Furthermore, methane treatment reduced the phosphorylated $\mathrm{I} \kappa \mathrm{B}, \mathrm{NF}-\kappa \mathrm{B}$, and P38 MAPK in the liver, which consequently decreased the secretion of proinflammatory cytokines and increased the level of antioxidants.

3.1.3. Hepatic Ischemia/Reperfusion (I/R) Injury. Hepatic ischemia/reperfusion (I/R) injury is induced by initial deficiency of blood supply to the liver and succeeding recovery of perfusion and oxygenation [20]. Surgery, transplantation, and circulation shock can all lead to liver I/R injury [21-23]. Ye et al. suggested that methane protects the liver against I/R injury through antiapoptotic, antioxidative, and anti-inflammatory actions by measuring inflammation makers, oxidant stress, and tissue injury [24].

\subsection{Lung}

3.2.1. Acute Lung Injury (ALI). Acute lung injury (ALI) is a destructive complication of several diseases such as acute circulatory failure, burn, and infection and is regarded as the main cause of acute respiratory failure [25]. ALI is clinically characterized by progressive hypoxemia and respiratory distress syndrome. The hallmark of ALI is injury to pulmonary capillary endothelial cells and alveolar epithelial cells and the activation of the innate immune, leading to diffuse edema in pulmonary interstitial and alveolar [26]. Sun et al. showed that methane-rich saline protected the lipopolysaccharide- (LPS-) challenged ALI via antioxidative, antiinflammatory, and antiapoptotic effects, which had potential to be a new therapy for the treatment of ALI [27]. According to their results, it showed that the survival period was prolonged significantly after methane-rich saline treatment. The lung wet-to-dry (W/D) ratio and the number of inflammatory factors were reduced, and the levels of caspase- 3 and apoptotic index were decreased either. In addition, methanerich saline raised the antioxidants such as superoxide dismutase (SOD) and decreased the level of malondialdehyde (MDA) significantly, which proved the antioxidant property of methane.

\subsection{Central Nervous System}

3.3.1. Spinal Cord Ischemia-Reperfusion (IR) Injury. Spinal cord ischemia-reperfusion (IR) injury is a destructive complication of several diseases such as spinal surgical procedures, hypotension, thoracoabdominal aneurysms, and thoracic [28]. The succeeding central nervous system injuries, such as paralysis, are severer health problems that have been continuously troubling patients [29]. The antioxidant, antiinflammatory, and antiapoptotic properties of methane can also protect patients from spinal cord ischemia-reperfusion injury. Methane-rich saline (MRS) significantly decreased the level of inflammatory cytokines and oxidative products via the increased expression of nuclear factor erythroid 2 p45-related factor 2 (Nrf2) and downstream pathways related with the expressions of heme oxygenase (HO-1), SOD, catalase, and glutathione (GSH) at the onset of reperfusion. As a result of all these actions, neuronal apoptosis death was reduced and neurological function was preserved [10].

3.3.2. Acute Carbon Monoxide (CO) Poisoning-Induced Injury. $\mathrm{CO}$ poison is an important cause of the accidental death. Methane protects brain from acute $\mathrm{CO}$ poisoninginduced injury with the properties of antioxidant, antiinflammatory, and antiapoptotic. A finding suggested that methane reduced the level of inflammatory cytokines such as tumor necrosis factor- $\alpha$ (TNF- $\alpha$ ) and interleukin $1-\beta$ (IL-1 $\beta$ ) in the brain but had no effect on interleukin 6 (IL-6) expression. In addition, the oxidative products such as malondialdehyde (MDA), 3-nitrotyrosine (3-NT), and 8-hydroxydeoxyguanosine $(8-\mathrm{OHdG})$ were reduced after methane treatment while the amount of SOD in the hippocampus and cortex was decreased, which improved neuronal injury [30].

3.3.3. Spinal Cord Injury. Spinal cord injury (SCI) and the subsequent risk of paralysis have been considered as a severe problem in clinic [31]. The USA statistics showed that the incidence of SCI reached 54 to 3393 cases/1 million in 
2012, and mortality increased significantly when compared with that in 1993 [32]. There are various pathological mechanisms involve in SCI such as oxidative stress, inflammation [33], and apoptosis [34]. According to Wang et al. [35], methane can significantly decrease infarct area by reducing the pathological factor including oxidative stress, inflammation, and cell apoptosis following SCI. Additionally, the microglial activation can be significantly suppressed and hindlimb neurological function was preserved.

3.4. Immune System. The inflammatory disease is characterized as a pathological process caused by immune disorder including the dysfunction or excessive activation of immune system. Among the inflammatory diseases, sepsis and autoimmune colitis are regarded as serious problems clinically. The study of Zhang et al. [36] showed that methane-rich saline had the protective effect to inhibit some inflammatory signals caused by LPS in macrophages and suppress immune response in mice by intensifying IL-10 expression through PI3K/AKT/GSK-3 $\beta$ pathway. In conclusion, methane-rich saline treatment can alleviate endotoxin shock, bacteria-induced sepsis, and dextran-sulfate-sodiuminduced colitis in mice.

\subsection{Eye}

3.5.1. Retinal Ischemia/Reperfusion Injury (IRI). Retinal ischemia/reperfusion injury (IRI) plays an important role in glaucoma, retinal vascular occlusion, diabetic, and many other diseases that can cause damage to human vision [37-39]. It can ultimately lead to blindness through neuronal damaging [40]. And in the pathological process of retinal IRI, retinal ganglion cells are the most susceptible and are regarded as the dominating factor. The study of Liu et al. [41] has shown that methane treatment was a promising therapeutic way for retinal IRI. According to their study, the level of oxidative products was reduced and the antioxidant enzyme was increased in retinas after methane treatment. Meanwhile, methane treatment obviously attenuated apoptosis in the retina by affecting the expression of the apoptosis-related gene and the caspase activity was limited as well. Thus, methane shows a protective role for the retinal ganglion cell (RCG) loss and dysfunction of vision in terms of retinal ischemia/reperfusion injury.

3.5.2. Diabetic Retinopathy (DR). Diabetic retinopathy (DR) is the main microvascular complication of diabetes whose succeeding problems such as blindness still remains to be serious problems in developed countries [42]. The inflammation [43], oxidative stress [44], and apoptosis [45] are involved in the pathology of diabetic retinopathy. The expression of TNF- $\alpha$, IL-1 $\beta$, glial fibrillary acidic protein (GFAP), and vascular endothelial growth factor (VEGF) in the DR retina were ameliorated after methane treatment. Moreover, the methane treatment upregulated retinal levels of miR-192-5p which is related to apoptosis and tyrosine kinase signaling pathway and also upregulated miR-335 which is related to proliferation, oxidative stress, and leukocyte. In terms of regulating miRNA, methane showed the protective effect on DR [45].
3.6. Motor System. The definition of overexercise is excessively prolonged or intense exercise, and many factors are associated with overload training including supercompensation and lack of recovery. Overexercise can lead to severe systemic disorders, such as rhabdomyolysis, acute kidney function failure, and systemic inflammatory response [46]. A study of Xin et al. showed that the methane-rich saline can promote the motor ability of rats such as treadmill running time and ameliorated exercise-related damage in gastrocnemius. At the meantime, the level of lactate acid and urea nitrogen in blood was reduced after methane treatment and the level of creatine kinase in plasma was decreased. Thus, methane may have a protective effect on the motor system in rats [47].

\subsection{Cardiovascular System}

3.7.1. Myocardial Infarction (MI). Myocardial infarction (MI) caused by coronary artery occlusion is the most common cardiovascular disease and a main cause of death worldwide [48]. It was found that methane-rich saline treatment can significantly ameliorate the apoptosis of cardiocytes and inhibit the subsequent myocardial remodeling. Thus, methane treatment can improve the cardiac function during the MI. And it is also found that the protective properties of methane-rich saline may be via its antioxidative, anti-inflammatory, antiapoptotic, and antiremodeling activities [9].

\subsection{Skin}

3.8.1. Ischemia/Reperfusion (I/R) Injury-Induced Flap Loss. Skin flap transfer is a basic plastic surgery method, which is used widely in trauma surgeries and plastic surgeries. Some problems remain to be solved by skin flap transfer, and the most serious problem among them is I/R injury-induced flap loss [49]. According to previous studies, methane-rich saline may serve as a novel promising therapeutic agent for improving skin flap survival through the effects that suppressed apoptosis after transplantation and attenuate I/R injury. It was shown that a better blood perfusion with less inflammatory infiltration and cell apoptosis was established in the flaps after the treatment of methane and thus the survival area was increased significantly. Moreover, the apoptosis-related expressions including p-ASK-1, p-JNK, Bax, and caspase-3 activity were reduced by the methane treatment [50].

\subsection{Gastrointestinal System}

3.9.1. Irritable Bowel Syndrome (IBS). Methane was considered to be inert in biological field. However, more and more evidences have shown that methane is involved in many intestinal diseases and also be regarded as a detection of intestinal diseases according to the clinical data [51]. Irritable bowel syndrome (IBS) is a group of symptoms-including abdominal pain and changes in the pattern of bowel movements without any evidence of underlying damage and it can occur over years [52]. In different region, morbidity of IBS varies from $7 \%$ to $21 \%$ [53]. The cause of IBS still remains unclear but abnormalities occur in the gut flora, which 
happens after the infection is considered as a pathway of IBS [54]. Mechanism research has shown that methane takes part in constriction and velocity of the tract small intestinal and ileum. Moreover, studies in different animals have shown that methane can augment intestinal contractile function and subsequently slow the intestinal transit. Additionally, study in the guinea pig ileum showed that the peristaltic velocity was decreased and contraction amplitude was increased significantly after methane treatment [55-57]. In this way, researchers believe that methanogen and their products methane take part in the process of IBS.

3.9.2. Intestinal Ischemia/Reperfusion Injury. The study of Boros et al. [8] provides evidence that methane inhalation can decrease the ischemia/reperfusion injury in intestine by involving in leukocyte activation and having a protective effect on oxidative and nitrative stress. According to the study, methane reduced the tissue damage index and the intestinal pCO2 gap. Moreover, methane treatment reduced the myeloperoxidase (MPO) activity and the intestinal oxidant stress levels. And also in the vitro experiment, the protective properties of methane were proven. Generally, the study shows that methane has properties of anti-inflammatory and antioxidant and has a potential to be a medicine for intestinal I/R injury.

3.9.3. Acute Pancreatitis. Acute pancreatitis (AP) is a sudden inflammation in the pancreas and pancreatic acinar cell necrosis following the activation of pancreatin. The mortality of AP can be high. According to the study of Xie et al. [58], methane showed a protective property in cerulein-induced acute pancreatitis model. And the researchers further found out that the level of inflammation, oxidant, and apoptosis appeared to be reduced.

\section{Discussion}

Scientists have already revealed a few biological properties of methane in inflammation, oxidative stress, and apoptosis. Through these properties, methane can influence several pathological processes including I/R injury and sepsis. What is the exact mechanism underlying the protective properties of methane? The answer is unclear. So far, different researchers have come up with different hypotheses. Boros et al. [8] proposed that methane might accumulate at the interfaces of cell membranes and change the physicochemical properties or the situ functionality of proteins embedded in the environment. Kai et al. [59] assumed the membrane pathways including $G$ protein, membrane, or receptormediated signaling and acetylcholine-activated ion channel kinetics may be involved in the mechanism that methane has shown in the previous studies. Fink [60] came up with several speculations to explain the biological effects of methane. In his speculations, cellular receptor, special oxygenase, and the formation of small amounts of the reactive alcohol, methanol, and/or changes in the redox milieu of the cell might be involved in the mechanism of the biological effects of methane. Since the mechanism of the protective effects is not clear, we discussed the protective properties of methane with an analysis of 15 studies (Table 1).
4.1. Anti-Inflammation. Inflammation is characterized by an increasing production of proinflammatory cytokines, leukocyte recruitment, and systemic and local regulation of leukocyte reactions [62]. A suitable balance of the inflammation process will lead to a defense reaction to the harmful target whereas the imbalance will lead to damage to the organism [63].

According to previous studies, inflammatory-related production during the tissue injury can be suppressed by methane treatment. Methane treatment influences some important pathway in activation of proinflammatory cytokines in lymphocytes and then regulates the cytokines. Yao et al. [16] showed that methane-rich saline may activate the PI3K-AKT-GSK-3 $\beta$ pathway to induce IL-10 expression and produce anti-inflammatory effects via the NF- $\kappa \mathrm{B}$ and MAPK pathways. Additionally, Wang et al. [10] indicated that methane reduced the level of inflammation by increasing the expression of Nrf2 and its downstream pathways.

4.2. Antioxidant. Oxidative stress is defined by an imbalance between the generation of free radical agent, like reactive oxygen species (ROS), and biological defenses that detoxify the free radical intermediates. The control of ROS production and antioxidant defense balance is necessary for normal cell function since oxidative take part in many pathological processes including I/R injury [64], cancer [65], and even neurological diseases [66]. ROS can initiate cell apoptosis or necrosis and the possible mechanism including DNA dissociation and lipid oxidation. Methane protects organism from oxidant in two aspects. On the one hand, it can raise the level of antioxidant factor such as SOD. On the other hand, methane can decrease oxidant factors like MDA and 3-NT. Moreover, the antioxidant effect may be related with the regulation of Nrf2 expression and oxidant-related miRNA like miR-335.

4.3. Antiapoptotic. Apoptosis is a process of programmed cell death that occurs in multicellular organisms and is important for homeostasis in multicellular life forms. In physiological manner, apoptosis diminishes harmed or transformed cells and needs for controlling of cell numbers, tissue, and organ morphology. Apoptosis is a highly regulated and controlled process that confers advantages during an organism's lifecycle. Lots of pathways are involved in the process of apoptosis, including Bcl-2/Bax and caspase system, and any disorder regulation of apoptosis often leads to cancer and tissue disorders. Song et al. [50] found that the level of Bcl-2 can be raised after the methane treatment. Additionally, the decline of JNK and ASK-1 showed to have the property to raise the level of $\mathrm{Bcl}-2$ in the I/R mice model. Overall, methane shows an antiapoptosis effect by decreasing expression levels of activated ASK-1, JNK, and Bax and the increasing expression of Bcl-2. Here, we summarized indicators which were used to identify the properties of methane (Table 2).

4.4. Methane, Hydrogen, and Other Gases. Since Robert Furchgott, Louis Ignarro, and Ferid Murad shared the noble prize in medicine for their discoveries concerning "nitric oxide as a signaling molecule in the cardiovascular system" in 1998, more and more attention has been paid to the 
TABLE 1: The studies in this review.

\begin{tabular}{|c|c|c|c|}
\hline $\begin{array}{l}\text { Organs or } \\
\text { systems }\end{array}$ & Animal models & Reference & Mechanism \\
\hline \multirow{3}{*}{ Liver } & $\begin{array}{l}\text { (1) Carbon tetrachloride-induced } \\
\text { acute liver injury }\end{array}$ & Yao et al. [16] & 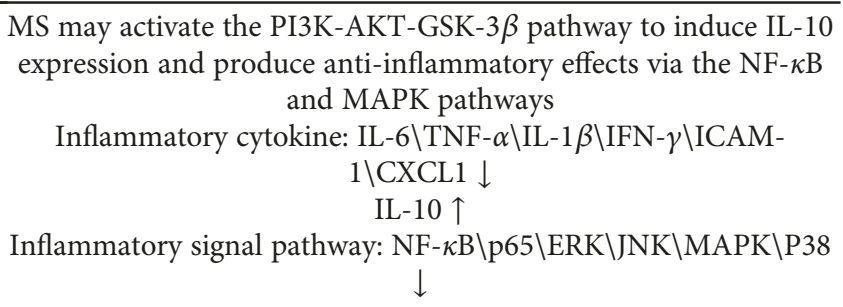 \\
\hline & $\begin{array}{l}\text { (2) Concanavalin A-induced } \\
\text { autoimmune hepatitis }\end{array}$ & He et al. [19] & $\begin{array}{c}\text { Oxidant: MDA } \backslash 8-\mathrm{OHdG} \downarrow \\
\text { Antioxidant: SOD } \backslash \mathrm{CAT} \uparrow \\
\text { Inflammatory cytokine: TNF- } \alpha \backslash \mathrm{IFN}-\gamma \backslash \mathrm{IL}-6 \backslash \mathrm{IL}-1 \beta \downarrow \\
\text { IL- } 10 \uparrow \\
\text { Inflammatory signal pathway: I } \kappa \mathrm{B} \backslash \mathrm{NF}-\kappa \mathrm{B} \backslash \mathrm{P} 38 \backslash \mathrm{MAPK} \downarrow\end{array}$ \\
\hline & $\begin{array}{l}\text { (3) Hepatic ischemia/reperfusion } \\
\text { injury }\end{array}$ & Ye et al. [24] & $\begin{array}{c}\text { Oxidant: MDA } \backslash 8 \text {-OHdG } \downarrow \\
\text { Antioxidant: SOD } \uparrow \\
\text { Inflammatory cytokine: TNF- } \alpha \backslash \text { IL- } 6 \downarrow \\
\text { Apoptosis: caspase-3 } \downarrow\end{array}$ \\
\hline Lung & $\begin{array}{l}\text { (4) Lipopolysaccharide-induced } \\
\text { acute lung injury }\end{array}$ & Sun et al. [27] & $\begin{array}{c}\text { Oxidant: MDA } \downarrow \\
\text { Antioxidant: SOD } \uparrow \\
\text { Inflammatory cytokine: TNF- } \alpha \backslash \text { IL-6 } \downarrow \\
\text { Apoptosis: TUNEL staining cells } \downarrow\end{array}$ \\
\hline
\end{tabular}

MS increases the expression of Nrf2 and downstream HO-1, SOD, catalase, and GSH, inhibiting the production of inflammatory cytokine, oxidative products, and glial activation.

(5) Spinal cord ischemia-reperfusion injury

Wang et al. [35]

Central nervous system

(6) Acute carbon monoxide poisoning injury

Shen et al. [30]

(7) Spinal cord injury

Wang et al. [10]

(8) Endotoxin shock Bacteria-induced sepsis dextran-sulfate-sodiuminduced colitis in mice

(9) Retinal ischemia/reperfusion injury

Liu et al. [41]

Eye

(10) Diabetic retinopathy

Wu et al. [61]
Oxidant: MDA \3-NT \GSSG \H2O2

Antioxidant: HO-1 $\backslash \mathrm{SOD} \backslash$ catalase $\backslash \mathrm{GSH} \uparrow$

Inflammatory cytokine: TNF- $\alpha \backslash$ IL- $1 \beta \backslash$ ICAM- $1 \backslash$ CXCL $1 \backslash$ MPO $\downarrow$ Inflammatory signal pathway: NF- $\kappa \mathrm{B} \backslash \mathrm{p} 65 \downarrow$ Apoptosis: caspase-9 $\backslash$ caspase-3\MMP9 $\downarrow$

\section{Nrf2 $\uparrow$}

Oxidant: MDA $\backslash 3-\mathrm{NT} \backslash 8-\mathrm{OHdG} \downarrow$ Antioxidant: SOD $\uparrow$

Inflammatory cytokine: TNF- $\alpha \backslash$ IL- $1 \beta \downarrow$ Apoptosis: caspase-9 $\backslash$ caspase-3\MMP9 $\downarrow$

Oxidant: MDA $\downarrow$

Antioxidant: SOD $\uparrow$

Inflammatory cytokine: TNF- $\alpha \backslash$ IL-6\IL- $1 \beta \downarrow$ Apoptosis: TUNEL staining cells $\backslash$ caspase- $3 \downarrow$

MS limits LPS-induced NF- $\kappa$ B/MAPK signal in macrophages and suppress immune response in mice by enhancing PI3K/AKT/GSK$3 \beta$-mediated IL-10 expression

Inflammatory cytokine: TNF- $\alpha \backslash$ IL-6\IL- $1 \beta \downarrow$ IL-10 $\uparrow$

Oxidant: MDA \4-HNE $\backslash 8-\mathrm{OHdG} \downarrow$ Antioxidant: SOD $\backslash \mathrm{CAT} \backslash \mathrm{GPX} \uparrow$ Apoptosis-related genes: $\mathrm{bcl} 2 \uparrow$ Bax $\downarrow$

Apoptosis: caspase-9 $\backslash$ caspase-3\MMP9 $\downarrow$ Inflammatory cytokine: TNF- $\alpha \backslash \mathrm{IL}-1 \beta \backslash \mathrm{VEGF} \backslash \mathrm{GFAP} \downarrow$ Apoptosis-related miRNA: miR-192-5p $\downarrow$

Oxidant-related miRNA: miR-335 $\downarrow$

Injury-related biomarker: $\mathrm{CK} \backslash \mathrm{UN} \downarrow$ Antioxidant: T-AOC $\uparrow$

Motor system (11) One-time exhaustive exercise Xin et al. [47]
Inflammatory cytokine: TNF- $\alpha \backslash$ IL- $1 \beta \backslash \mathrm{IL}-6 \downarrow$ 
TABLE 1: Continued.

\begin{tabular}{|c|c|c|c|}
\hline $\begin{array}{l}\text { Organs or } \\
\text { systems }\end{array}$ & Animal models & Reference & Mechanism \\
\hline $\begin{array}{l}\text { Cardiovascular } \\
\text { system }\end{array}$ & (12) Myocardial ischemia injury & Chen et al. [9] & $\begin{array}{c}\text { Oxidant: MDA } \backslash 8 \text {-OHdG } \downarrow \\
\text { Antioxidant: SOD } \backslash \mathrm{GSH} \uparrow \\
\text { Inflammatory cytokine: TNF- } \alpha \backslash \mathrm{IL}-1 \beta \backslash \mathrm{MPO} \downarrow \\
\text { Apoptosis-related pathways: Bcl- } 2 / \mathrm{Bax} \backslash \mathrm{ASK}-1 / \mathrm{JNK} \\
\text { Apoptosis: caspase-9 } \backslash \text { caspase- } 3 \backslash \mathrm{Bax} \downarrow\end{array}$ \\
\hline Skin & $\begin{array}{l}\text { (13) Skin flap ischemia/reperfusion } \\
\text { injury }\end{array}$ & $\begin{array}{l}\text { Song et al. } \\
\quad[50]\end{array}$ & 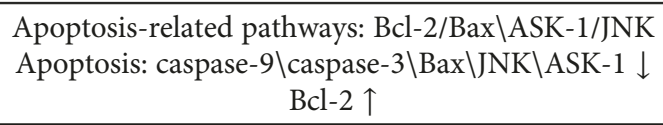 \\
\hline \multirow{2}{*}{$\begin{array}{l}\text { Gastrointestinal } \\
\text { system }\end{array}$} & $\begin{array}{l}\text { (14) Intestinal ischemia/reperfusion } \\
\text { injury }\end{array}$ & Boros et al. [8] & $\begin{array}{c}\text { Oxidant: } \mathrm{MPO} \backslash \mathrm{SOX} \downarrow \\
\mathrm{NOx} \uparrow\end{array}$ \\
\hline & (15) Acute pancreatitis & Xie et al. [58] & $\begin{array}{c}\text { Inflammatory cytokine: TNF- } \alpha \backslash \text { IL- } 6 \backslash \text { IFN }-\gamma \backslash \text { IL-10 } \downarrow \\
\text { Oxidant: MDA } \downarrow \\
\text { Antioxidant: SOD } \uparrow\end{array}$ \\
\hline
\end{tabular}

TABLE 2: The indicators that are used to identify the properties of methane.

\begin{tabular}{|c|c|c|}
\hline Pathology & Makers & Trend \\
\hline Antioxidase & $\begin{array}{l}\text { SOD } \\
\text { CAT } \\
\text { GSH }\end{array}$ & Increase \\
\hline Oxidative stress & $\begin{array}{c}\text { MDA } \\
\text { 4-HNE } \\
\text { 8-OHdG } \\
\text { MPO } \\
\text { 3-NT } \\
\text { DAO }\end{array}$ & Decline \\
\hline Inflammation factor & $\begin{array}{c}\text { IL-1 } \beta \\
\text { IL-6 } \\
\text { ICAM-1 } \\
\text { IL-12 } \\
\text { TNF- } \alpha \\
\text { IFN- } \gamma \\
\text { CCL2 } \\
\text { CXCL1 }\end{array}$ & Decline \\
\hline Inflammation signal & $\begin{array}{c}\text { MAPK } \\
\text { Lyn-P } \\
\text { JNK } \\
\text { ERK } \\
\text { NF- } \kappa B\end{array}$ & Decline \\
\hline Apoptosis & $\begin{array}{c}\text { TUNEL } \\
\text { Caspase-3 } \\
\text { Caspase-9 } \\
\text { Caspase-12 } \\
\text { Bcl-2 }\end{array}$ & Decline \\
\hline Nuclear factor & $\mathrm{Nrf2}$ & Activation \\
\hline
\end{tabular}

biological function of endogenous gases and lots of studies have confirmed that there are still many gases of important role in physiology in addition to nitric oxide (NO).

Carbon monoxide ( $\mathrm{CO}$ ) and hydrogen sulfide (H2S), two small molecules produced by human cells, are considered to have the similar function with NO in relaxation of vascular smooth muscle. NO can bind with the iron atom in the heme-containing protein and then change the protein to catalyze the guanosine triphosphate into the cyclic guanosine monophosphate which is also called the "second messenger" $[67,68]$. The activation effect of CO is related with largeconductance calcium-activated potassium. However, the mechanism behind the activation of H2S is not so clear and adenosine triphosphate-sensitive potassium channel in vascular smooth muscle cells may be involved in the process [69].

Although $\mathrm{NO}, \mathrm{CO}$, and $\mathrm{H} 2 \mathrm{~S}$ have been regarded as the "star molecule" and has been studied most commonly, its chemical property is quite different from methane. Methane is quite unreactive and needs a critical condition, such as high temperature or ultraviolet. On the other hand, methane is a simple nontoxic asphyxiant for its unreactive characteristic but $\mathrm{NO}, \mathrm{CO}$, and $\mathrm{H} 2 \mathrm{~S}$ have more active property in biological field; in other words, they can be toxic sometimes.

In many aspects, hydrogen (H2) functions are in similar ways with methane. As a mild molecule, hydrogen can hardly disturb the normal reaction in the cell and also have a biological advantage by anti-inflammatory, antioxidant, and antiapoptosis [11, 70-72]. However, as more advanced researches about hydrogen have been done in past decades, hydrogen was found with more biological effects than methane and the mechanism of these effects is clearer than methane. Here, we list the comparison of methane and hydrogen (Table 3) and hope that more studies can be taken about methane in the future. As shown in Table 3, the delivery methods of hydrogen varied more. And the protective properties of methane in renal system and metabolic disease need to be demonstrated in the future. What is more, the mechanism behind these effects also needs to be clarified in the future.

4.5. Prospects of Methane. The study of biological function of methane develops rapidly. Methane, the most abundant organic compound on earth, was ignored in the medical field for decades. However, it has become a hotspot in therapeutic gas field. Recently, researchers have discovered some protective effect of methane and focus on the therapeutic function in I/R injury and inflammation disorder. Although lots of work has been done recently, there are still many problems unsolved. Firstly, the mechanism of several protective effects 
TABLE 3: The comparison between hydrogen and methane in biological field.

\begin{tabular}{|c|c|c|}
\hline & Hydrogen & Methane \\
\hline Delivery methods & $\begin{array}{l}\text { Inhalation of hydrogen gas [11] } \\
\text { Oral ingestion by drinking hydrogen water [71] } \\
\text { Injection of hydrogen-rich saline [73] } \\
\text { Direct incorporation of molecular hydrogen by diffusion: } \\
\text { eye-drop and bath }[74,75]\end{array}$ & $\begin{array}{l}\text { Inhalation of methane gas [8] } \\
\text { Injection of methane-rich saline [9] }\end{array}$ \\
\hline $\begin{array}{l}\text { The biological effects } \\
\text { [76] }\end{array}$ & $\begin{array}{l}\text { (1) Protective effects against reperfusion injury } \\
\text { (2) Protective effects against neurodegeneration } \\
\text { (3) Preventive effects against metabolic syndrome } \\
\text { (4) Suppressive effects on inflammation } \\
\text { (5) Mitigation of side effects in treatments of cancers } \\
\text { (6) Effects on dermatomyositis and mitochondrial diseases } \\
\text { (7) Mitigating effects of hemodialysis } \\
\text { (8) Effects on acute erythematous skin diseases } \\
\text { (9) Effects on exercise }\end{array}$ & $\begin{array}{l}\text { (1) Protective effects against reperfusion injury } \\
{[8,9,24,27,35,41,50]} \\
\text { (2) Suppressive effects on inflammation } \\
{[16,19,27,36,58]} \\
\text { (3) Effects on diabetic complication [41] } \\
\text { (4) Effects on exercise [47] } \\
\text { (5) Protective effects on carbon monoxide } \\
\text { toxicity [30] }\end{array}$ \\
\hline Mechanism [76] & $\begin{array}{l}\text { (1) Direct reduction of hydroxyl radicals with molecular hydrogen } \\
\text { (2) Direct reduction of peroxynitrite with molecular hydrogen } \\
\text { to regulate } \\
\text { (3) Indirect reduction of oxidative stress by regulating } \\
\text { gene expression } \\
\text { (4) Regulation of gene expression of proinflammatory cytokines } \\
\text { and hormones } \\
\text { (5) Regulation of other genes } \\
\text { (6) Modulation of signaling }\end{array}$ & $\begin{array}{l}\text { (1) Direct reduction of inflammation-related } \\
\text { pathways } \\
\text { (2) Direct reduction of oxidant-related pathways } \\
\text { (3) Direct reduction of apoptosis-related } \\
\text { pathways } \\
\text { (4) Regulation of gene expression of oxidant- } \\
\text { related genes }\end{array}$ \\
\hline
\end{tabular}

is still unclear despite different scholars have made different hypotheses. More pathways need to be detected. Secondly, since methane is effective in terms of being against inflammation, oxidative stress, and apoptosis, will methane become a potential medicine in cancer and other more diseases? Thirdly, according to the characteristic that methane is able to penetrate the cell membrane, can methane act as a signal molecule such as NO? Additionally, we also need to do a lot of research to formulate a standard that can provide the optimum dose, timing, and delivery methods. What is more, the disadvantage and toxicity of methane should be studied carefully before application.

\section{Conflicts of Interest}

The authors declare that there is no conflict of interest regarding the publication of this article.

\section{Authors' Contributions}

Yifan Jia participated in the research design and writing the paper. Zeyu Li participated in the literature review and writing the paper. They contributed equally to the paper. Chang Liu and Jingyao Zhang provided substantial advice in designing the study and revising the paper. Yifan Jia and Zeyu Li contribute equally to the paper.

\section{Acknowledgments}

The authors are indebted to all individuals who participated in or helped with this research project. This study was supported by funding from "the National Nature Science Foundation of China” (Grant no. 81601672), "the Project of
Innovative Research Team for Key Science and Technology in Shaanxi province" (Grant no. 2013KCJ-23), and "the Fundamental Research Funds for the Central Universities" (Grant no. 1191320114).

\section{References}

[1] "Methane," http://en.wikipedia.org/wiki/Methane.

[2] J. H. Bond Jr., R. R. Engel, and M. D. Levitt, "Factors influencing pulmonary methane excretion in man. An indirect method of studying the in situ metabolism of the methane-producing colonic bacteria," The Journal of Experimental Medicine, vol. 133, no. 3, pp. 572-588, 1971.

[3] D. Roccarina, E. C. Lauritano, M. Gabrielli, F. Franceschi, V. Ojetti, and A. Gasbarrini, "The role of methane in intestinal diseases," The American Journal of Gastroenterology, vol. 105, no. 6, pp. 1250-1256, 2010.

[4] K. Triantafyllou, C. Chang, and M. Pimentel, "Methanogens, methane and gastrointestinal motility," Journal of Neurogastroenterology and Motility, vol. 20, no. 1, pp. 31-40, 2014.

[5] C. Chassard and C. Lacroix, "Carbohydrates and the human gut microbiota," Current Opinion in Clinical Nutrition and Metabolic Care, vol. 16, no. 4, pp. 453-460, 2013.

[6] P. B. Eckburg, E. M. Bik, C. N. Bernstein et al., "Diversity of the human intestinal microbial flora," Science, vol. 308, no. 5728, pp. 1635-1638, 2005.

[7] P. W. Lepp, M. M. Brinig, C. C. Ouverney, K. Palm, G. C. Armitage, and D. A. Relman, "Methanogenic Archaea and human periodontal disease," Proceedings of the National Academy of Sciences of the United States of America, vol. 101, no. 16, pp. 6176-6181, 2004.

[8] M. Boros, M. Ghyczy, D. Érces et al., "The anti-inflammatory effects of methane," Critical Care Medicine, vol. 40, no. 4, pp. 1269-1278, 2012. 
[9] O. Chen, Z. Ye, Z. Cao et al., "Methane attenuates myocardial ischemia injury in rats through anti-oxidative, anti-apoptotic and anti-inflammatory actions," Free Radical Biology \& Medicine, vol. 90, pp. 1-11, 2016.

[10] L. Wang, Y. Yao, R. He et al., "Methane ameliorates spinal cord ischemia-reperfusion injury in rats: antioxidant, antiinflammatory and anti-apoptotic activity mediated by $\mathrm{Nrf} 2$ activation," Free Radical Biology \& Medicine, vol. 103, pp. 69-86, 2017.

[11] I. Ohsawa, M. Ishikawa, K. Takahashi et al., "Hydrogen acts as a therapeutic antioxidant by selectively reducing cytotoxic oxygen radicals," Nature Medicine, vol. 13, no. 6, pp. 688694, 2007.

[12] W. Bernal, G. Auzinger, A. Dhawan, and J. Wendon, "Acute liver failure," The Lancet, vol. 376, no. 9736, pp. 190-201, 2010.

[13] M. Khashab, A. J. Tector, and P. Y. Kwo, "Epidemiology of acute liver failure," Current Gastroenterology Reports, vol. 9, no. 1, pp. 66-73, 2007.

[14] W. M. Lee, "Etiologies of acute liver failure," Seminars in Liver Disease, vol. 28, no. 2, pp. 142-152, 2008.

[15] J. G. O'Grady, “Acute liver failure," Postgraduate Medical Journal, vol. 81, no. 953, pp. 148-154, 2005.

[16] Y. Yao, L. Wang, P. Jin et al., "Methane alleviates carbon tetrachloride induced liver injury in mice: anti-inflammatory action demonstrated by increased PI3K/Akt/GSK-3 $\beta$-mediated IL-10 expression," Journal of Molecular Histology, vol. 48, no. 4, pp. 301-310, 2017.

[17] M. P. Manns, A. W. Lohse, and D. Vergani, “Autoimmune hepatitis - update 2015," Journal of Hepatology, vol. 62, no. 1, pp. S100-S111, 2015.

[18] K. Harada, N. C. Hiep, and H. Ohira, "Challenges and difficulties in pathological diagnosis of autoimmune hepatitis," Hepatology Research, vol. 47, no. 10, pp. 963-971, 2017.

[19] R. He, L. Wang, J. Zhu et al., "Methane-rich saline protects against concanavalin A-induced autoimmune hepatitis in mice through anti-inflammatory and anti-oxidative pathways," Biochemical and Biophysical Research Communications, vol. 470, no. 1, pp. 22-28, 2016.

[20] T. Kalogeris, C. P. Baines, M. Krenz, and R. J. Korthuis, "Cell biology of ischemia/reperfusion injury," International Review of Cell and Molecular Biology, vol. 298, pp. 229-317, 2012.

[21] C. X. Li, K. T. Ng, Y. Shao et al., "The inhibition of aldose reductase attenuates hepatic ischemia-reperfusion injury through reducing inflammatory response," Annals of Surgery, vol. 260, no. 2, pp. 317-328, 2014.

[22] Y. Zhai, R. W. Busuttil, and J. W. Kupiec-Weglinski, "Liver ischemia and reperfusion injury: new insights into mechanisms of innate-adaptive immune-mediated tissue inflammation," American Journal of Transplantation, vol. 11, no. 8, pp. 1563-1569, 2011.

[23] M. Cour, J. Loufouat, M. Paillard et al., "Inhibition of mitochondrial permeability transition to prevent the post-cardiac arrest syndrome: a pre-clinical study," European Heart Journal, vol. 32, no. 2, pp. 226-235, 2011.

[24] Z. Ye, O. Chen, R. Zhang et al., "Methane attenuates hepatic ischemia/reperfusion injury in rats through antiapoptotic, anti-inflammatory, and antioxidative actions," Shock, vol. 44, no. 2, pp. 181-187, 2015.

[25] K. Ladha, M. F. Vidal Melo, D. J. McLean et al., "Intraoperative protective mechanical ventilation and risk of postoperative respiratory complications: hospital based registry study," $B M J$, vol. 351, article h3646, 2015.

[26] E. R. Johnson and M. A. Matthay, "Acute lung injury: epidemiology, pathogenesis, and treatment," Journal of Aerosol Medicine and Pulmonary Drug Delivery, vol. 23, no. 4, pp. 243-252, 2010.

[27] A. Sun, W. Wang, X. Ye et al., "Protective effects of methanerich saline on rats with lipopolysaccharide-induced acute lung injury," Oxidative Medicine and Cellular Longevity, vol. 2017, Article ID 7430193, 12 pages, 2017.

[28] D. E. Cramer, P. C. Maher, D. B. Pettigrew, and C. Kuntz IV, "Major neurologic deficit immediately after adult spinal surgery: incidence and etiology over 10 years at a single training institution," Journal of Spinal Disorders \& Techniques, vol. 22, no. 8, pp. 565-570, 2009.

[29] S. A. LeMaire, M. D. Price, S. Y. Green, S. Zarda, and J. S. Coselli, "Results of open thoracoabdominal aortic aneurysm repair," Annals of Cardiothoracic Surgery, vol. 1, no. 3, pp. 286-292, 2012.

[30] M. Shen, D. Fan, Y. Zang et al., "Neuroprotective effects of methane-rich saline on experimental acute carbon monoxide toxicity," Journal of the Neurological Sciences, vol. 369, pp. 361-367, 2016.

[31] S. Selvarajah, E. R. Hammond, and E. B. Schneider, "Trends in traumatic spinal cord injury," JAMA, vol. 314, no. 15, p. 1643, 2015.

[32] N. B. Jain, G. D. Ayers, E. N. Peterson et al., "Traumatic spinal cord injury in the United States, 1993-2012," JAMA, vol. 313, no. 22, pp. 2236-2243, 2015.

[33] M. Su, H. Guan, F. Zhang, Y. Gao, X. Teng, and W. Yang, "HDAC6 regulates the chaperone-mediated autophagy to prevent oxidative damage in injured neurons after experimental spinal cord injury," Oxidative Medicine and Cellular Longevity, vol. 2016, Article ID 7263736, 13 pages, 2016.

[34] C. M. Li, S. J. Xie, T. Wang, W. B. Du, Z. B. Yang, and R. F. Quan, "Effects of electro-acupuncture on neuronal apoptosis and associative function in rats with spinal cord injury," Zhongguo Gu Shang, vol. 28, no. 8, pp. 733-738, 2015.

[35] W. Wang, X. Huang, J. Li et al., "Methane suppresses microglial activation related to oxidative, inflammatory, and apoptotic injury during spinal cord injury in rats," Oxidative Medicine and Cellular Longevity, vol. 2017, Article ID 2190897, 11 pages, 2017.

[36] X. Zhang, N. Li, H. Shao et al., "Methane limit LPS-induced $\mathrm{NF}-\kappa \mathrm{B} / \mathrm{MAPKs}$ signal in macrophages and suppress immune response in mice by enhancing PI3K/AKT/GSK-3 $\beta$-mediated IL-10 expression," Scientific Reports, vol. 6, no. 1, article 29359, 2016.

[37] N. N. Osborne, R. J. Casson, J. P. Wood, G. Chidlow, M. Graham, and J. Melena, "Retinal ischemia: mechanisms of damage and potential therapeutic strategies," Progress in Retinal and Eye Research, vol. 23, no. 1, pp. 91-147, 2004.

[38] N. N. Osborne, M. Ugarte, M. Chao et al., "Neuroprotection in relation to retinal ischemia and relevance to glaucoma," Survey of Ophthalmology, vol. 43, Supplement 1, pp. S102-S128, 1999.

[39] G. H. Bresnick, G. De Venecia, F. L. Myers, J. A. Harris, and M. D. Davis, "Retinal ischemia in diabetic retinopathy," Archives of Ophthalmology, vol. 93, no. 12, pp. 1300-1310, 1975.

[40] A. Piras, D. Gianetto, D. Conte, A. Bosone, and A. Vercelli, "Activation of autophagy in a rat model of retinal ischemia 
following high intraocular pressure," PLoS One, vol. 6, no. 7, article e22514, 2011.

[41] L. Liu, Q. Sun, R. Wang et al., "Methane attenuates retinal ischemia/reperfusion injury via anti-oxidative and antiapoptotic pathways," Brain Research, vol. 1646, pp. 327-333, 2016.

[42] X. F. Zhu and H. D. Zou, "PEDF in diabetic retinopathy: a protective effect of oxidative stress," Journal of Biomedicine and Biotechnology, vol. 2012, Article ID 580687, 8 pages, 2012.

[43] C. M. Cheung, M. Vania, M. Ang, S. P. Chee, and J. Li, "Comparison of aqueous humor cytokine and chemokine levels in diabetic patients with and without retinopathy," Molecular Vision, vol. 18, pp. 830-837, 2012.

[44] F. Giacco and M. Brownlee, "Oxidative stress and diabetic complications," Circulation Research, vol. 107, no. 9, pp. 1058-1070, 2010.

[45] P. M. Martin, P. Roon, T. K. Van Ells, V. Ganapathy, and S. B. Smith, "Death of retinal neurons in streptozotocin-induced diabetic mice," Investigative Ophthalmology \& Visual Science, vol. 45, no. 9, pp. 3330-3336, 2004.

[46] J. B. Kreher and J. B. Schwartz, "Overtraining syndrome: a practical guide," Sports Health: A Multidisciplinary Approach, vol. 4, no. 2, pp. 128-138, 2012.

[47] L. Xin, X. Sun, and S. Lou, "Effects of methane-rich saline on the capability of one-time exhaustive exercise in male SD rats," PLoS One, vol. 11, no. 3, article e0150925, 2016.

[48] A. S. Go, D. Mozaffarian, V. L. Roger et al., "Heart disease and stroke statistics-2014 update: a report from the American Heart Association," Circulation, vol. 129, no. 3, pp. e28-e292, 2014.

[49] W. Z. Wang, R. C. Baynosa, and W. A. Zamboni, "Update on ischemia-reperfusion injury for the plastic surgeon: 2011," Plastic and Reconstructive Surgery, vol. 128, no. 6, pp. 685e692e, 2011.

[50] K. Song, M. Zhang, J. Hu et al., "Methane-rich saline attenuates ischemia/reperfusion injury of abdominal skin flaps in rats via regulating apoptosis level," BMC Surgery, vol. 15, no. 1, p. 92, 2015.

[51] A. Attaluri, M. Jackson, J. Valestin, and S. S. Rao, "Methanogenic flora is associated with altered colonic transit but not stool characteristics in constipation without IBS," The American Journal of Gastroenterology, vol. 105, no. 6, pp. 1407-1411, 2010.

[52] W. D. Chey, J. Kurlander, and S. Eswaran, "Irritable bowel syndrome: a clinical review," Journal of the American Medical Association, vol. 313, no. 9, pp. 949-958, 2015.

[53] R. M. Lovell and A. C. Ford, "Global prevalence of and risk factors for irritable bowel syndrome: a meta-analysis," Clinical Gastroenterology and Hepatology, vol. 10, no. 7, pp. 712721.e4, 2012, e4.

[54] M. Simren, G. Barbara, H. J. Flint et al., "Intestinal microbiota in functional bowel disorders: a Rome foundation report," Gut, vol. 62, no. 1, pp. 159-176, 2013.

[55] J. Jahng, I. S. Jung, E. J. Choi, J. L. Conklin, and H. Park, “The effects of methane and hydrogen gases produced by enteric bacteria on ileal motility and colonic transit time," Neurogastroenterology \& Motility, vol. 24, no. 2, pp. 185-e92, 2012.

[56] M. Pimentel, H. C. Lin, P. Enayati et al., "Methane, a gas produced by enteric bacteria, slows intestinal transit and augments small intestinal contractile activity," American Journal of Physiology. Gastrointestinal and Liver Physiology, vol. 290, no. 6, pp. G1089-G1095, 2006.
[57] A. B. Sahakian, S. R. Jee, and M. Pimentel, "Methane and the gastrointestinal tract," Digestive Diseases and Sciences, vol. 55, no. 8, pp. 2135-2143, 2010.

[58] Q. Xie, M. Fei, Z. Fa et al., "Methane-rich saline alleviates cerulein-induced acute pancreatitis by inhibiting inflammatory response, oxidative stress and pancreatic apoptosis in mice," International Immunopharmacology, vol. 51, pp. 17-24, 2017.

[59] T. Kai, K. A. Jones, and D. O. Warner, "Halothane attenuates calcium sensitization in airway smooth muscle by inhibiting G-proteins," Anesthesiology, vol. 89, no. 6, pp. 1543-1552, 1998.

[60] M. P. Fink, "Pharmacological effects of inhaled methane: plausible or not?," Critical Care Medicine, vol. 40, no. 4, pp. 1379-1380, 2012.

[61] J. Wu, R. Wang, Z. Ye et al., "Protective effects of methane-rich saline on diabetic retinopathy via anti-inflammation in a streptozotocin-induced diabetic rat model," Biochemical and Biophysical Research Communications, vol. 466, no. 2, pp. 155-161, 2015.

[62] E. Galkina and K. Ley, "Immune and inflammatory mechanisms of atherosclerosis," Annual Review of Immunology, vol. 27, no. 1, pp. 165-197, 2009.

[63] A. Ortega-Gomez, M. Perretti, and O. Soehnlein, "Resolution of inflammation: an integrated view," EMBO Molecular Medicine, vol. 5, no. 5, pp. 661-674, 2013.

[64] D. L. Carden and D. N. Granger, "Pathophysiology of ischaemia-reperfusion injury," The Journal of Pathology, vol. 190, no. 3, pp. 255-266, 2000.

[65] S. Jin, Y. Wu, S. Deng, J. Zhang, and X. Q. Chen, "Oxidants and antioxidants in metabolic syndrome and cancer," Oxidative Medicine and Cellular Longevity, vol. 2014, Article ID 178962, 3 pages, 2014.

[66] R. Filograna, M. Beltramini, L. Bubacco, and M. Bisaglia, "Anti-oxidants in Parkinson's disease therapy: a critical point of view," Current Neuropharmacology, vol. 14, no. 3, pp. 260-271, 2016.

[67] A. Friebe and D. Koesling, "Regulation of nitric oxidesensitive guanylyl cyclase," Circulation Research, vol. 93, no. 2, pp. 96-105, 2003.

[68] M. P. Fink, "Modulating the L-arginine-nitric oxide pathway in septic shock: choosing the proper point of attack," Critical Care Medicine, vol. 27, no. 9, pp. 2019-2022, 1999.

[69] C. W. Leffler, H. Parfenova, J. H. Jaggar, and R. Wang, "Carbon monoxide and hydrogen sulfide: gaseous messengers in cerebrovascular circulation," Journal of Applied Physiology, vol. 100, no. 3, pp. 1065-1076, 2006.

[70] M. Kajiya, M. J. Silva, K. Sato, K. Ouhara, and T. Kawai, "Hydrogen mediates suppression of colon inflammation induced by dextran sodium sulfate," Biochemical and Biophysical Research Communications, vol. 386, no. 1, pp. 11-15, 2009.

[71] K. Nagata, N. Nakashima-Kamimura, T. Mikami, I. Ohsawa, and S. Ohta, "Consumption of molecular hydrogen prevents the stress-induced impairments in hippocampus-dependent learning tasks during chronic physical restraint in mice," Neuropsychopharmacology, vol. 34, no. 2, pp. 501-508, 2009.

[72] B. M. Buchholz, D. J. Kaczorowski, R. Sugimoto et al., "Hydrogen inhalation ameliorates oxidative stress in transplantation induced intestinal graft injury," American Journal of Transplantation, vol. 8, no. 10, pp. 2015-2024, 2008. 
[73] J. Cai, Z. Kang, K. Liu et al., "Neuroprotective effects of hydrogen saline in neonatal hypoxia-ischemia rat model," Brain Research, vol. 1256, pp. 129-137, 2009.

[74] H. Oharazawa, T. Igarashi, T. Yokota et al., "Protection of the retina by rapid diffusion of hydrogen: administration of hydrogen-loaded eye drops in retinal ischemia-reperfusion injury," Investigative Ophthalmology \& Visual Science, vol. 51, no. 1, pp. 487-492, 2010.

[75] K. Noda, N. Shigemura, Y. Tanaka et al., "A novel method of preserving cardiac grafts using a hydrogen-rich water bath," The Journal of Heart and Lung Transplantation, vol. 32, no. 2, pp. 241-250, 2013.

[76] S. Ohta, "Molecular hydrogen as a preventive and therapeutic medical gas: initiation, development and potential of hydrogen medicine," Pharmacology \& Therapeutics, vol. 144, no. 1, pp. 1-11, 2014. 


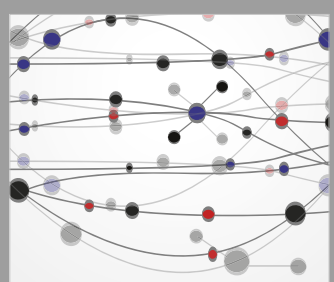

The Scientific World Journal
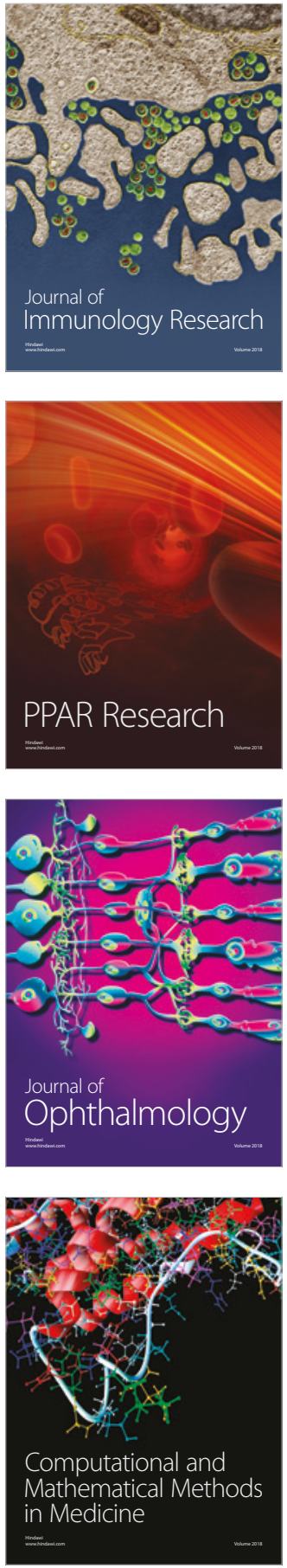

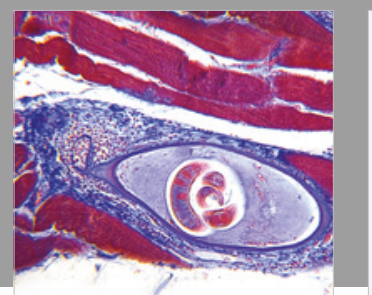

Gastroenterology Research and Practice

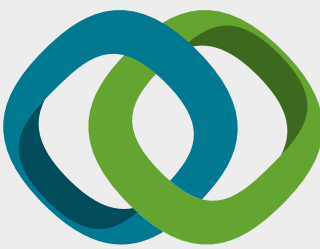

\section{Hindawi}

Submit your manuscripts at

www.hindawi.com
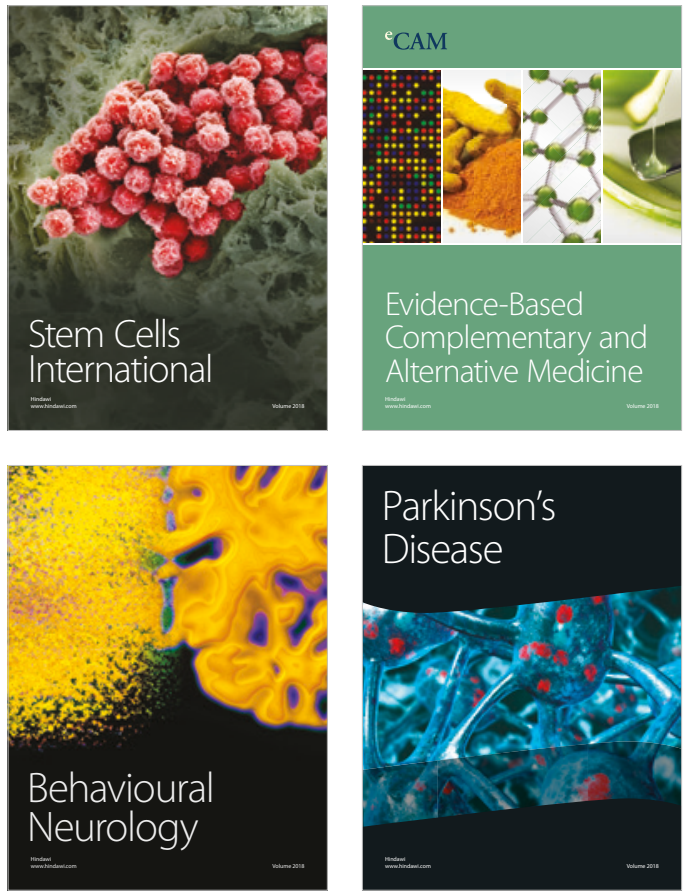

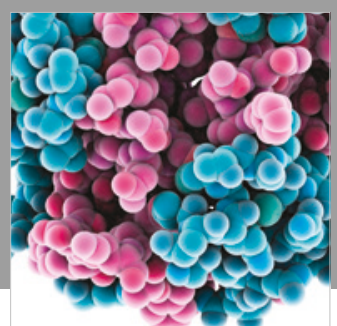

ournal of

Diabetes Research

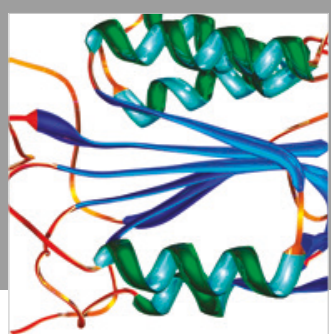

Disease Markers
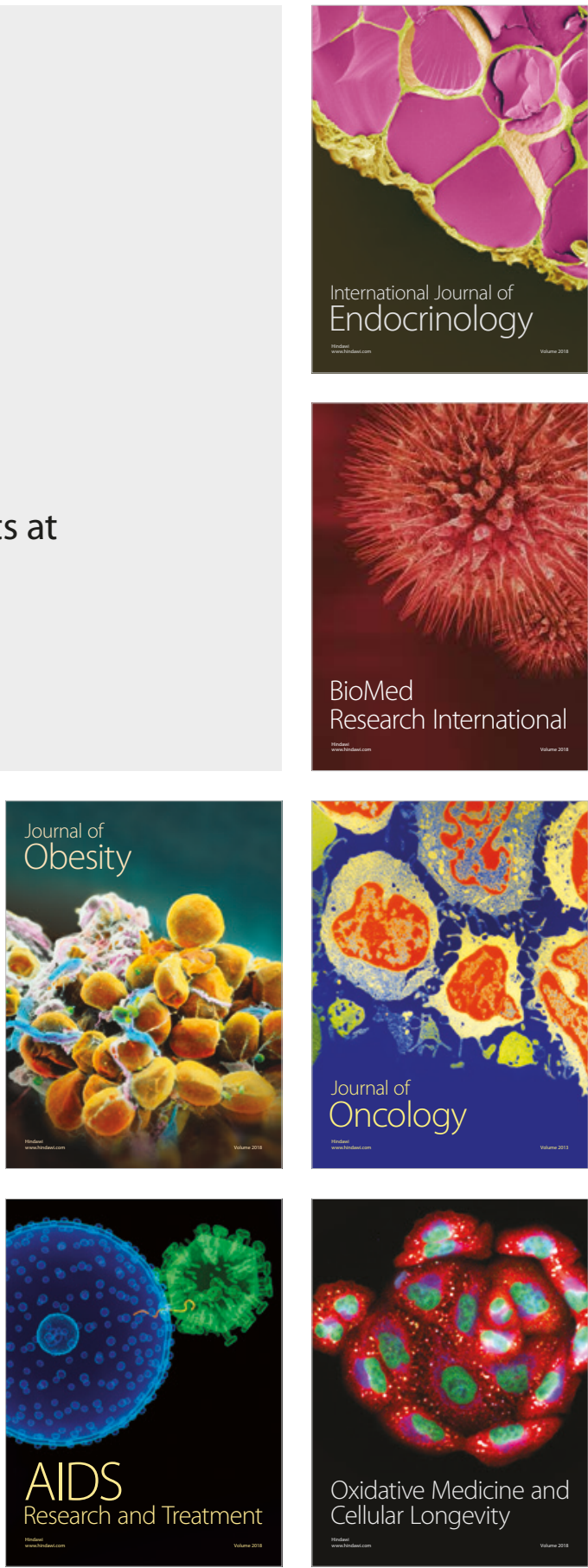